\title{
Combined targeting of AKT and mTOR synergistically inhibits proliferation of hepatocellular carcinoma cells
}

Nicole Grabinski ${ }^{1 \dagger}$, Florian Ewald ${ }^{2 \dagger}$, Bianca T Hofmann ${ }^{1,5}$, Katharina Staufer ${ }^{2,4}$, Udo Schumacher $^{3}$, Björn Nashan ${ }^{2}$ and Manfred Jücker ${ }^{1 *}$

\begin{abstract}
Background:

Due to the frequent dysregulation of the PI3KJAKT/mTOR signaling pathway, mTOR represents a suitable therapeutic target in hepatocellular carcinoma (HCC). However, emerging data from clinical trials of HCC patients indicate that mTOR inhibition by RAD001 (Everolimus) alone has only moderate antitumor efficacy which may be due to the feedback activation of AKT after mTOR inhibition. In this study, we analyzed the effects of dual inhibition of mTOR and AKT on the proliferation of HCC cell lines. In addition, we measured the feedback activation of each of the AKT isoforms after mTOR inhibition in HCC cell lines and their enzymatic activity in primary samples from HCC patients.
\end{abstract}

\section{Methods:}

The activation status of specific AKT isoforms in human HCC samples and corresponding healthy liver tissue was analyzed using an AKT isoform specific in vitro kinase assay. AKT isoform activation after mTOR inhibition was analyzed in three HCC cell lines (Hep3B, HepG2 and Huh7), and the impact of AKT signaling on proliferation after mTOR inhibition was investigated using the novel AKT inhibitor MK-2206 and AKT isoform specific knockdown cells.

\section{Results:}

AKT isoforms become differentially activated during feedback activation following RAD001 treatment. The combination of mTOR inhibition and AKT isoform knockdown showed only a weak synergistic effect on proliferation of HCC cell lines. However, the combinatorial treatment with RAD001 and the pan AKT inhibitor MK-2206 resulted in a strong synergism, both in vitro and in vivo. Moreover, by analyzing primary HCC tissue samples we were able to demonstrate that a hotspot mutation (H1047R) of PI3KCA, the gene encoding the catalytic subunit of PI3K, was associated with increased in vitro kinase activity of all AKT isoforms in comparison to healthy liver tissue of the patient.

\section{Conclusion:}

Our results demonstrate that dual targeting of mTOR and AKT by use of RAD001 and the pan AKT inhibitor MK-2206 does effectively inhibit proliferation of HCC cell lines. These data suggest that combined treatment with RAD001 and MK-2206 may be a promising therapy approach in the treatment of hepatocellular carcinoma.

Keywords: Hepatocellular carcinoma, RAD001, MK-2206, Proliferation, AKT, AKT isoform kinase assay

\footnotetext{
*Correspondence: juecker@uke.uni-hamburg.de

${ }^{\dagger}$ Equal contributors

${ }^{1}$ Center for Experimental Medicine, Institute of Biochemistry and Signal

Transduction, University Medical Center Hamburg-Eppendorf, Martinistr. 52,

Hamburg 20246, Germany

Full list of author information is available at the end of the article
} 


\section{Background}

Hepatocellular carcinoma (HCC) is the third leading cause of cancer mortality worldwide, with an increasing incidence in the United States and Europe [1,2]. Only 30-40\% of patients are amenable to potentially curative therapies, such as surgical resection, because of the often advanced stage of disease at the time of diagnosis. Today, the multikinase inhibitor sorafenib is the only systemic therapy to improve survival in these patients [3]. However, prognosis of advanced HCC remains poor, and new effective therapeutic strategies are urgently needed.

The PI3K/AKT/mTOR signaling pathway is a promising target with respect to its frequent dysregulation in hepatocellular carcinoma and its central role in regulating cell proliferation, migration, survival and angiogenesis $[4,5]$. Aberrant mTOR signaling has been detected in up to $48 \%$ of hepatocellular carcinoma, and a correlation between poor outcome and mTOR signaling activation has been shown [6]. Phosphorylation of AKT at S473 was detected in up to $71 \%$ of HCC samples, and associated with invasion, metastasis, and vascularization of $\mathrm{HCC}$ [7].

Several inhibitors targeting mTOR are tested in clinical trials at present [8]. Clinical trials revealed that the rapamycin derivative RAD001 (Everolimus) is sufficient to improve the overall survival of patients with metastatic renal carcinoma and subependymal giant cell astrocytoma [9,10]. Emerging data from clinical trials of HCC patients indicate that RAD001, even well tolerated, has only moderate antitumor efficacy in HCC patients [11,12]. A negative feedback loop resulting in the activation of AKT following mTOR inhibition has been observed in a variety of cancer cell lines and human tumor samples of colon and breast cancer [13]. Since the antitumor efficacy of rapalogues in patients is modest, activation of AKT as a central regulator of cell growth is a potentially unfavorable event resulting from cancer treatment with mTOR inhibitors [14]. AKT feedback is thought to be mediated by inhibition of p70S6 kinase activity, resulting in an increase in IRS-1 (insulin receptor substrate 1) expression [15]. Since it has been demonstrated that cells lacking IRS-1 also show increased AKT phosphorylation following mTOR inhibition, other mechanisms of feedback activation have been proposed [16]. An increase in the phosphorylation of receptor tyrosine kinases, i.e. EGFR, HER2, HER3 among others, following treatment with rapamycin was demonstrated [17] and may represent an IRS-1-independent way of increased AKT signaling.

The serine/threonine kinase AKT is a key player of the regulatory network of the cell and affects virtually all cellular activities, including growth, survival, movement, differentiation and metabolism [18,19]. Currently, three mammalian isoforms of AKT (AKT1/PKB $\alpha, \mathrm{AKT} 2 / \mathrm{PKB} \beta$, and AKT3/PKBY) have been identified [20,21]. The isoforms share a high degree of structural homology with human AKT1 having 81 and 83\% amino acid identity with AKT2 and AKT3, respectively. Although there is evidence for partial functional overlap of the AKT isoforms, studies on isoform specific knockout mice revealed their distinct functional roles underlined by diverse signaling cascades, thereby controlling cell growth, metabolism, cell proliferation and survival $[22,23]$. Specific functions of each isoform have also been proposed in human carcinoma cell lines and mouse models [24-26].

In this study, we analyzed the AKT feedback activation following RAD001 treatment in three HCC cell lines with different AKT isoform expression levels. For the first time differential changes in AKT isoform activity following RAD001 treatment were documented.

Furthermore, the importance of AKT isoform specific signaling following mTOR inhibition has been investigated by combination of the MTOR inhibitor RAD001 either with the new orally active allosteric pan AKT inhibitor MK-2206 [27], or AKT isoform specific knockdown cells. Here, we demonstrate that inhibition of mTOR and AKT in combination acts synergistically on cell proliferation of HCC cells. Our results suggest that dual targeting of mTOR and AKT might be a new promising therapeutic approach in the treatment of hepatocellular carcinoma.

\section{Results}

\section{Feedback activation of AKT following mTOR inhibition} with RAD001 is concentration- and time-dependent

In order to investigate feedback activation of AKT following mTOR inhibition we analyzed the activation of the $\mathrm{PI} 3 \mathrm{~K} / \mathrm{AKT} / \mathrm{mTOR}$ pathway in the three HCC cell lines Hep3B, HepG2 and Huh7. All HCC cell lines showed a constitutive activation of the PI3K/AKT/mTOR pathway as demonstrated by phosphorylation of AKT (S473 and T308), mTOR (S2448), representing mTORC1 activity [28], and pS6 (S240/S244) which is a downstream substrate of mTORC1 and S6-kinase (Figure 1A). Treatment of the HCC cell lines with various concentrations of RAD001 resulted in a marked suppression of phosphorylation of mTOR (S2448) and the downstream S6 protein (S240/244) (Figure 1A). Interestingly, we observed a differential feedback activation of AKT in a concentrationdependent manner after treatment with RAD001 for 24 hours with respect to phosphorylation of AKT at residues S473 versus T308 (1B). The feedback phosphorylation at S473 showed a peak level at $1 \mathrm{nM}$ (Hep3B and Huh7) and only a lower or even no increase at all at higher concentrations of RAD001. In contrast, feedback phosphorylation of T308 was observed at low and high concentrations of RAD001 (Figure 1A, B).

Because we did not observe an increase in the phosphorylation of AKT at S473 in HCC cells after treatment with a higher concentration of $100 \mathrm{nM}$ RAD001 at 24 hours (Figure 1B), we performed a more detailed time kinetic 
from 3 up to 72 hour (Figure $1 \mathrm{C}$ and D, Additional file 1: Figure S1). No significant time dependent change in pAKT (S473) expression was observed in Hep3B cells at $100 \mathrm{nM}$ RAD001 (Additional file 1: Figure S1). Surprisingly, a short term increase of pAKT (S473) expression was evident in both Huh7 (Figure 1C) and HepG2 (Figure 1D) cells with a peak between 3 to $12 \mathrm{~h}$ after treatment with RAD001. The basal pAKT (S473) expression level was reestablished after $24 \mathrm{~h}$ and no further increase was observed at $48 \mathrm{~h}$ posttreatment. The decrease of pAKT (S473) represents

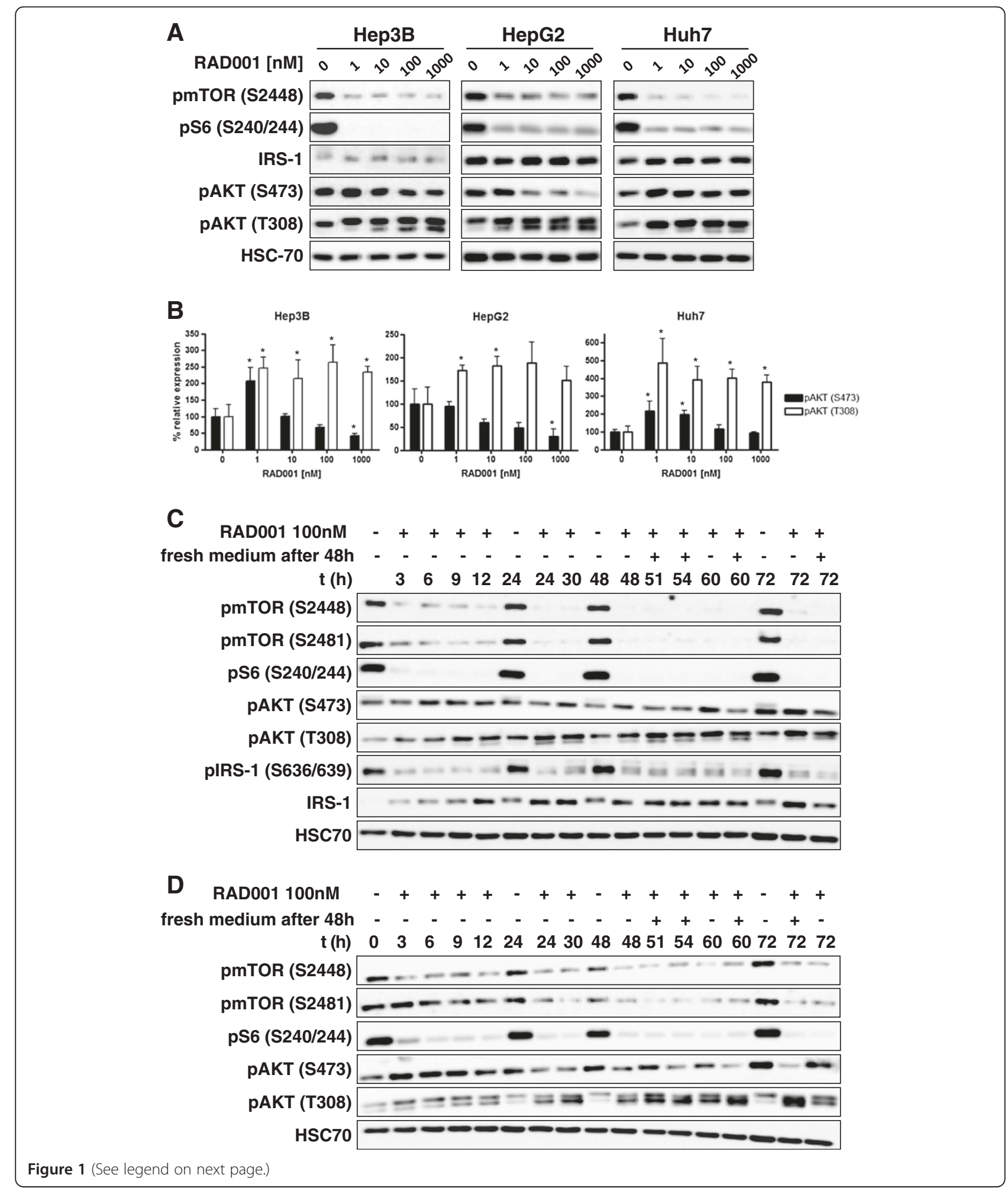


(See figure on previous page.)

Figure 1 Feedback activation of AKT after mTOR inhibition is time- and dose dependent. (A) HCC cell lines Hep3B, HepG2 and Huh7 were treated for $24 \mathrm{~h}$ with increasing concentrations of RAD001 as indicated. Phosphorylation status of mTOR and AKT was analyzed by Western blot with phospho specific antibodies. (B) Dose dependent expression of PAKT (S473) and pAKT (T308) after $24 \mathrm{~h}$ treatment with RAD001 was quantified from three independent experiments as shown in A. Columns, mean percentage of three independent experiments; bars, SD, ${ }^{*} p<$ 0.05. (C) Huh7 and (D) HepG2 cells were treated with $100 \mathrm{nM} \mathrm{RAD001} \mathrm{up} \mathrm{to} 72 \mathrm{~h}$, and cell lysates were prepared at the indicated time points. Where indicated, medium was removed after $48 \mathrm{~h}$ and replaced by fresh, $100 \mathrm{nM}$ RAD001 containing medium. HSC70 served as loading control.

inhibition of mTORC2 activity [29]. This is in line with previous studies showing suppressed mTORC2 assembly after prolonged incubation of cells with allosteric mTOR inhibitors [30]. In the case that the culture medium was replaced after $48 \mathrm{~h}$ with medium containing fresh RAD001, subsequent AKT feedback phosphorylation on S473 was absent or only weakly detectable 3 to $6 \mathrm{~h}$ after the addition of new RAD001 (Figure 1C and D). Conversely, there was a clear time-dependent increase in pAKT (T308), reaching its maximum after $>30 \mathrm{~h}$ of incubation. While cells treated one time only with RAD001 show elevated levels of pAKT (S473) after 60 and $72 \mathrm{~h}$, no increase of pAKT (S473) expression was observed after 60 and $72 \mathrm{~h}$ in cells re-treated with fresh culture medium after $48 \mathrm{~h}$ (Figure $1 \mathrm{C}$ and 1D). This late increase in pAKT (S473) might be due to degradation of RAD001 in culture medium, thereby possibly relieving mTORC2 complexes of RAD001mediated inhibition which was described before [31]. All results were confirmed in at least two independent experiments.

\section{Differential and isoform specific activation of AKT1, AKT2 and AKT3 during feedback activation after mTOR inhibition}

The regulation of AKT kinase activity involves phosphorylation of threonine residue 308 in the activation loop and serine residue 473 in the hydrophobic region $[32,33]$. Of note, phospho-specific AKT antibodies directed against S473 and T308 used here and in numerous other publications do not discriminate between the different AKT isoforms. Therefore, the representation of single AKT isoform activities measured by the expression of pAKT (S473) or (T308) with phosphoAKT specific antibodies remains unclear. A more detailed insight into the regulation of AKT isoforms may be interesting in the term of developing of AKT isoform specific inhibitors as anticancer drugs. To assess whether a specific AKT isoform becomes predominantly activated after RAD001 treatment, we first analyzed the expression of AKT isoforms in HCC cell lines. As shown in Figure 2A, all cell lines expressed AKT1 and AKT2, with the highest expression levels observed in Huh7 cells (Figure 2A). In contrast, AKT3 expression was restricted to Hep3B cells.
To reveal changes in AKT activity, an AKT isoformspecific, quantitative in vitro kinase assay was performed as described previously [24], using the same cell lysates as shown in Figure 1A. Since AKT3 was not detectable in HepG2 and Huh7 cells either by western blot or by immunoprecipitation technique using different AKT3 antibodies, we analyzed AKT3 kinase activity only in Hep3B cells. Interestingly, we observed a differential concentrationdependent pattern of AKT-isoform activation following RAD001 treatment for the three HCC cell lines analyzed. Hep3B cells showed a moderate increase in AKT2 activity, but no increase in AKT1 and AKT3 activity (Figure 2B). The increase in AKT2 activity was only observed at $1 \mathrm{nM}$ RAD001 but not at higher concentrations. In contrast, in HepG2 cells we observed an increase in AKT1 activity at all concentrations analyzed, whereas AKT2 kinase activity was decreased in a concentration-dependent manner. In Huh7 cells, RAD001 led to a 40- and 20-fold increase in AKT1 and AKT2 kinase activity after stimulation with 1 nM RAD001, respectively. Interestingly, a similar activation of both AKT isoforms was also observed after stimulation of these cells with the higher concentration of 10 and 100 nM RAD001 (Figure 2B) [34].

\section{Dual targeting of mTOR and AKT highly synergistically inhibits proliferation of HCC cell lines}

We next aimed to investigate the impact of AKT activity after RAD001 treatment. By use of MK-2206, a new highly potent allosteric pan-AKT inhibitor, we analyzed dual targeting of mTOR and AKT on proliferation of HCC cells. As shown in Figure 3A, AKT inhibitor MK-2206 reduced the phosphorylation of pAKT (S473) and (T308) in all HCC cell lines, with no preference for either phosphorylation site. Concomitant with the reduction in pAKT was a moderate reduction in phosphorylation of GSK3 $\beta$ at S9 and S6 at S235/246, albeit to a varying degree among the analyzed cell lines. To evaluate a potential synergistic effect of combined inhibition of mTOR and AKT, we used the method proposed by Chou and Talalay [35]. HCC cell lines were treated with RAD001, MK-2206, or a combination of both compounds with a fixed ratio of 1:5, over a broad range of clinically relevant concentrations. To exclude effects of plating density on proliferation, we established ideal plating densities for each cell line 


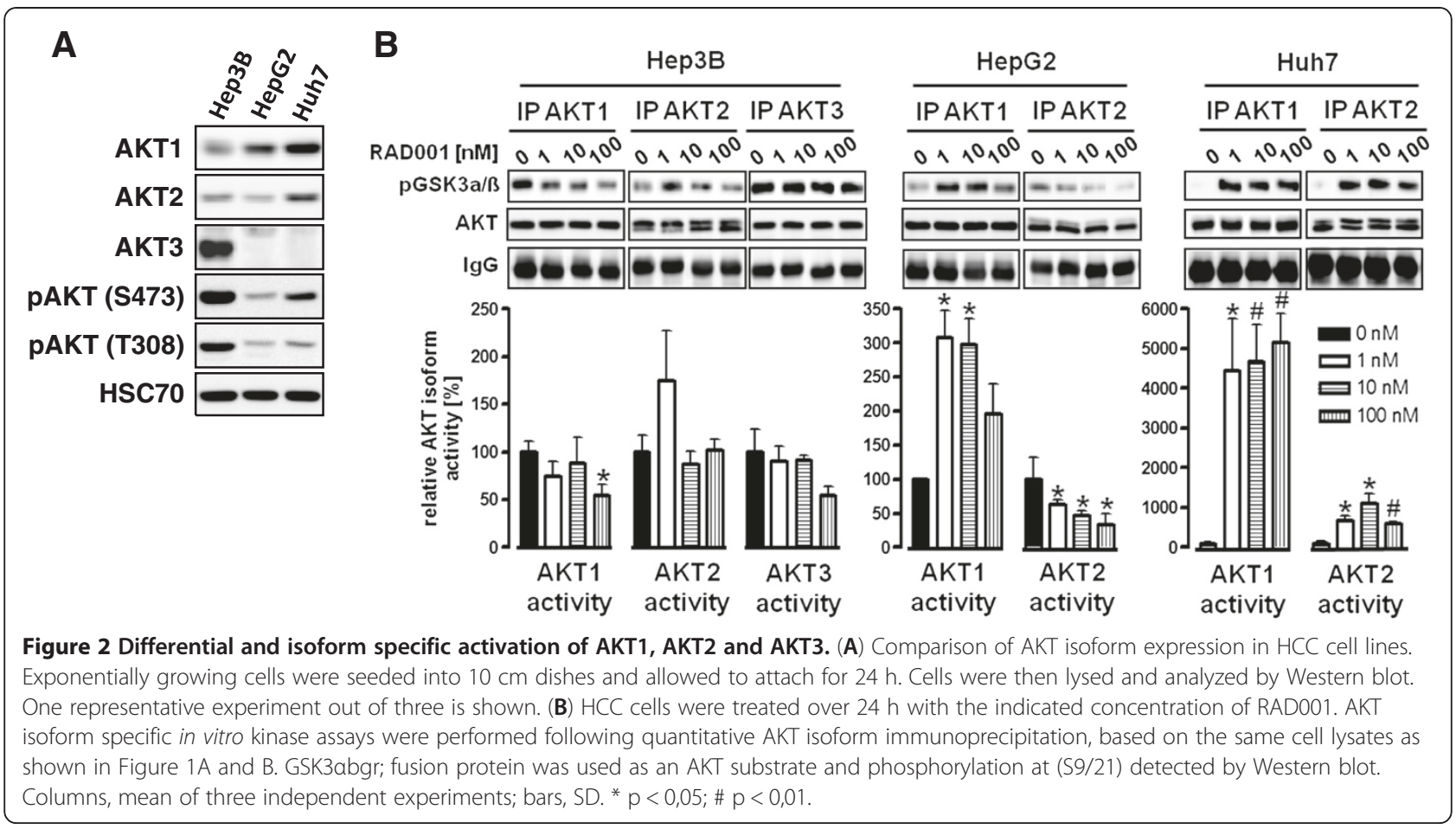

(Additional file 2: Figure S2). The importance of this step was underlined by a marked reduction of proliferation for cells reaching $>80 \%$ confluence.

Treatment with RAD001 over $72 \mathrm{~h}$ resulted in a significant decrease in proliferation of all cell lines, with HepG2 cells being least, and Huh7 being most sensitive to RAD001 (Figure 3B).In contrast to Huh7 and Hep3B, HepG2 cells harbor a mutation in N-ras (http://rcgdb. bioinf.uni-sb.de/MutomeWeb) which was discussed to contribute to RAD001 resistance [36]. We observed no significant dose dependent effects of RAD001 on proliferation for the concentrations between $1 \mathrm{nM}$ and $1000 \mathrm{nM}$ with the exception that HepG2 cells showed a non-significant trend towards stronger inhibition at higher concentrations of RAD001.

The anti-proliferative efficacy of AKT inhibitor MK-2206 alone was only weak with $\mathrm{IC}_{50}$ values of $3.7 \mu \mathrm{M}, 7.4 \mu \mathrm{M}$ and $3.1 \mu \mathrm{M}$ for Hep3B, HepG2 and Huh7, respectively (Additional file 3: Figure S3). However, combining RAD001 and MK-2206 led to a synergistic suppression of proliferation in all three cell lines, with Combination Index (CI) values indicating strong, or very strong synergism especially at moderate and higher concentrations of the two compounds (Figure 3D, Additional file 4: Figure S4). As shown in Figure 3E combining RAD001 and MK-2206 resulted in a significantly higher accumulation of cells in G0/G1 phase compared to each compound alone. An increase of cells in subG1 phase was present in all cell lines treated with the combination, indicating the presence of apoptotic cells.
Furthermore, since effects of RAD001 alone on proliferation were not dose dependent, we next tested whether synergistic effects were dependent on higher doses of RAD001. We therefore treated HCC cells with increasing concentrations of RAD001 alone or in combination with a fixed dose of MK-2206. As shown in Figure 3C, strong synergistic effects of dual mTOR- and AKT-inhibition could already be achieved at doses of RAD001 as low as $1 \mathrm{nM}$. Interestingly, no RAD001 concentration-dependent differences in the synergistic effect of RAD001 and MK-2206 were observed, although low doses of RAD001,i.e. $1 \mathrm{nM}$, resulted in the strongest increase in phosphorylation of AKT at S473 (Figure 1A, B) and AKT isoform activity (Figure 2B).

\section{Knockdown of a single AKT isoform is synergistic with mTOR inhibition on proliferation of HCC cells}

To analyze the impact of single AKT isoforms on proliferation of HCC cell lines, we generated stable AKT1 and AKT2 knockdown cells for all three HCC cell lines. Since we were unable to detect AKT3 at protein level in HepG2 and Huh7 cells, AKT3 knockdown cells were only established for Hep3B cells (Figure 4A). Knockdown of AKT isoforms was highly effective, and no significant changes in the expression of the remaining AKT isoforms were detected as shown for Hep3B cells.

Next we compared the effect of MK-2206 and knockdown of single AKT isoforms on activation of AKT and mTOR signaling pathways in HCC cell lines (Figure 4B for Hep3B cells, Additional file 5: Figure S5 for HepG2 and 


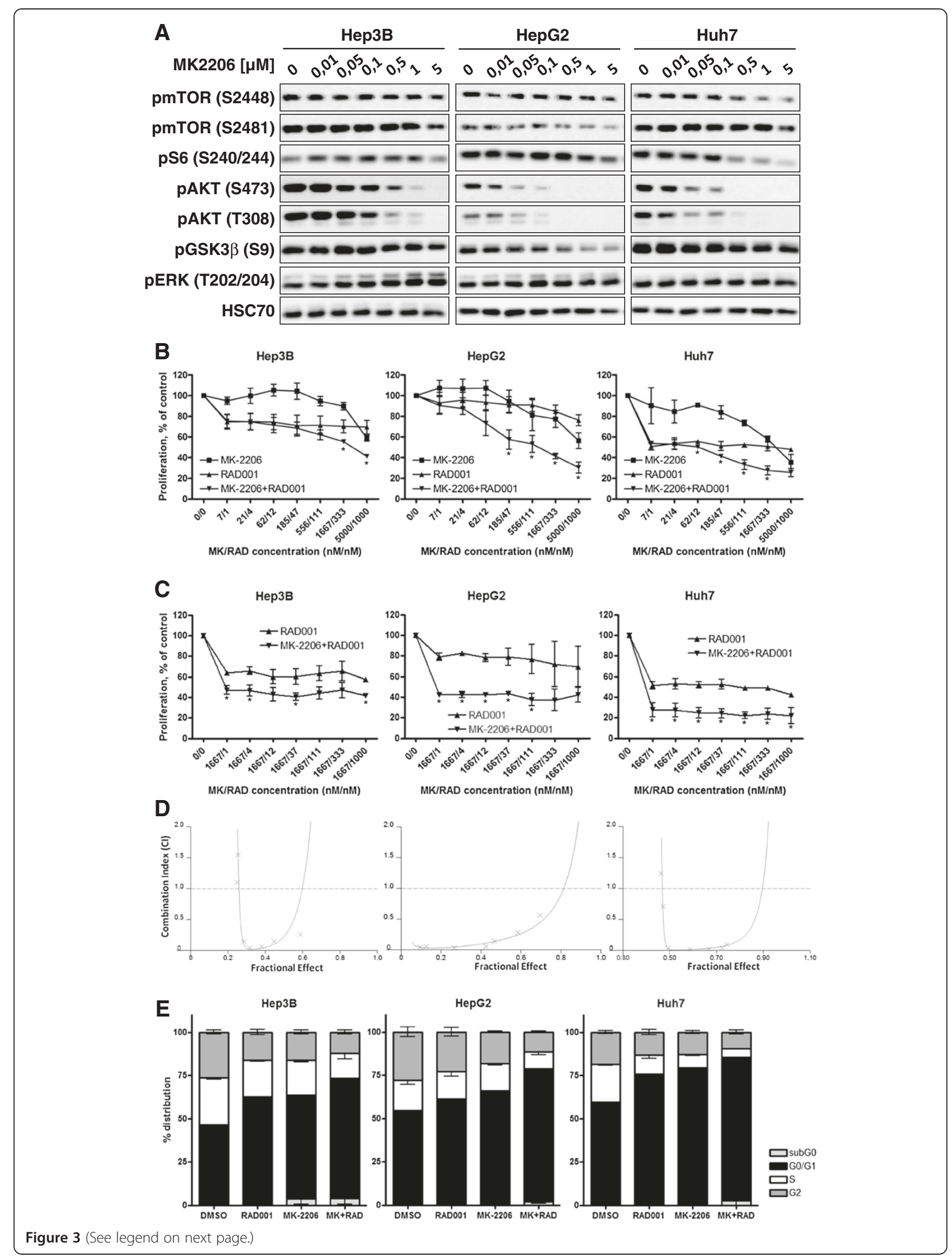


(See figure on previous page.)

Figure 3 Combining RAD001 with MK-2206 synergistically suppresses proliferation of HCC cell lines. (A) HCC cell lines were treated with the indicated concentration of MK-2206 over 24 h, and changes in mTOR- and AKT-signaling were analyzed by Western Blot. HSC70 served as loading control. (B) HCC cells were seeded into 96 well plates and incubated with increasing concentrations of either RAD001 (triangle), MK2206 (box), or a combination (inverted triangle) of both with a fixed ratio of 1:5. Controls were treated with DMSO only. Proliferation was analyzed after $72 \mathrm{~h} \mathrm{BrdU}$-incorporation. Asterisks indicate a significantly stronger inhibition of the drug combination compared to each compound alone, ${ }^{*} p<0.05$. (C) HCC cell lines were treated with RAD001 (triangle) or a combination of RAD001 and MK-2206 (inverted triangle) with a constant concentration of $1.7 \mu \mathrm{M}$ MK2206 for $72 \mathrm{~h}$. Cells treated with DMSO only served as control. Proliferation was analyzed as in (B). Each data point represents mean of at least three independent experiments, normalized to controls; bars, SD. Asterisks indicate a significantly stronger inhibition of the drug combination compared to each compound alone, ${ }^{*} p<0.05$. (D) Fractional effect plot for the effect of RAD001 and MK2206 as seen in (B). (E) Cell cycle analysis of HCC cell lines after $24 \mathrm{~h}$ treatment with $100 \mathrm{nM}$ RAD001, 1.7 MM MK-2206, or the combination of both, compared to DMSO treated controls. Colums: mean of one representative experiment, performed in triplicates; bars: SD. The drug combination resulted in a significant increase of cells in G0/G1 phase compared to each drug alone and compared to controls in all three cell lines $(p<0.05)$.

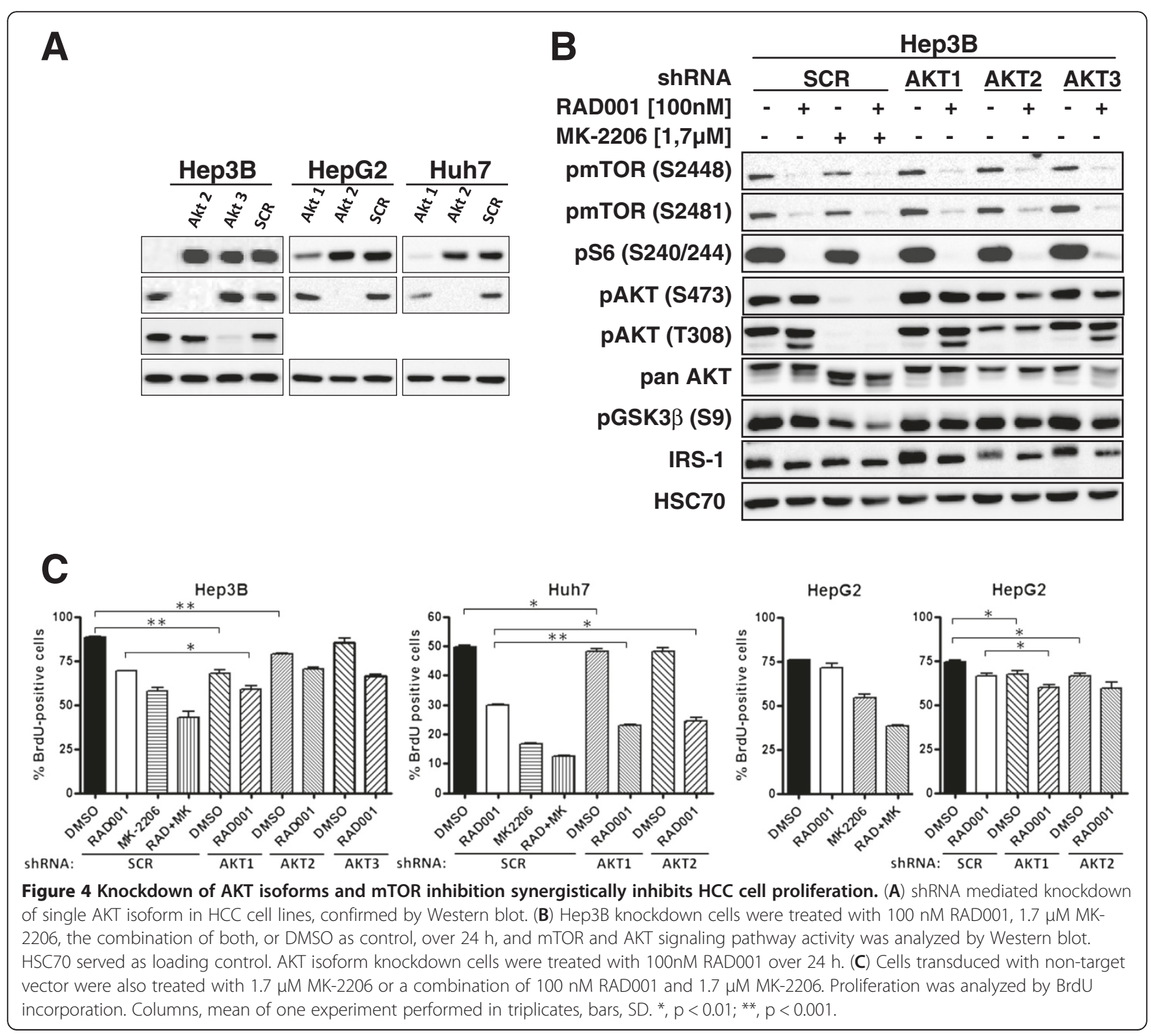


Huh7 cells). Treatment with $1.7 \mu \mathrm{M}$ MK-2206 completely abolished phosphorylation of AKT and decreased phosphorylation of GSK3 $\beta$ at serine residue 9. Knockdown of AKT2 led to a reduced phosphorylation of AKT at S473and T308 in all three cell lines, whereas knockdown of AKT1 and AKT3 did not result in reduced levels of phosphorylated AKT (Figure 4B, Additional file 5: Figure S5).

To further investigate synergistic effects of combined mTOR and AKT isoform inhibition, AKT isoform knockdown cells were treated with 100 nM RAD001 or DMSO for $24 \mathrm{~h}$. In addition, control cells treated with $1.7 \mu \mathrm{M} \mathrm{MK}$ 2206 alone or in combination with $100 \mathrm{nM}$ of mTOR inhibitor RAD001 were analyzed. As shown in Figure 4C, knockdown of AKT1 led to a significant inhibition of proliferation of all investigated HCC cell lines, with the strongest effect observed in Hep3B cells. While depletion of AKT2 reduced proliferation of both, Hep3B and HepG2 cells, knockdown of AKT3 had no significant effect on proliferation of Hep3B cells. In combination with RAD001 knockdown of AKT1 resulted in a synergistic inhibition of proliferation of all HCC cell lines, whereas knockdown of AKT2 was only synergistic in Huh7 cells. Combining RAD001 with pan AKT inhibitor MK-2206 led to a markedly stronger reduction of cell proliferation than combining RAD001 with knockdown of any single AKT isoform.

\section{RAD001 and MK-2206 are highly synergistic in vivo}

Next, we analyzed the efficacy of dual treatment with RAD001 and MK-2206 in a subcutaneous HCC xenograft mouse model. As seen in Figure 5A, combining RAD001 and MK-2206 significantly prolonged survival of mice compared to placebo or each compound alone. Furthermore, a significant decrease in tumor volume compared to placebo was only observed in mice treated with the combination of RAD001 and MK-2206 (Figure 5B). Until 15 days post-treatment, no significant difference in mouse weight was observed between the four groups, indicating that the treatment was well tolerated. The decrease in the average weight at day 18 in placebo and MK-2206 treated mice reflects tumor cachexia due to tumor progression (Additional file 6: Figure S6). To confirm specific effects of RAD001 and MK-2206 on PI3K/AKT/mTOR signaling, tumor portions from one randomly chosen mouse per group were subjected to Western blot analysis. As seen in Figure 5C, RAD001 almost completely abolished phosphorylation of S6 at serine residue 240/244. Treatment with RAD001 slightly increased the phosphorylation of AKT at threonine residue 308, whereas treatment with MK-2206 suppressed the phosphorylation of AKT at both serine residue 473 and threonine residue 308.

\section{All AKT isoforms are activated in a HCC patient with mutated PI3K}

In order to identify genetic alterations in the PI3K/AKT/ mTOR signaling pathway in liver cancer, genomic DNA from 10 primary tumor samples of HCC patients were analysed by direct sequencing after PCR amplification. Yet, mutations in the regulatory $\mathrm{p} 85 \alpha$ subunit of $\mathrm{PI} 3 \mathrm{~K}$, the $\mathrm{PH}$ domain of the three AKT isoforms and specific domains of mTOR have not been analysed in HCC. The 47 exons of the sequenced genes PIK3R1 (p85 $\alpha$ subunit of PI3K), PIK3CA (catalytic subunit of PI3K) FRAP1 (mTOR), the three AKT isoforms (AKT1, AKT2, AKT3) and the genetic alterations identified within the $10 \mathrm{HCC}$ samples are summarized in Table 1. No genetic alterations have been identified in $A K T 1, A K T 2$ or $A K T 3$. A comparison with the

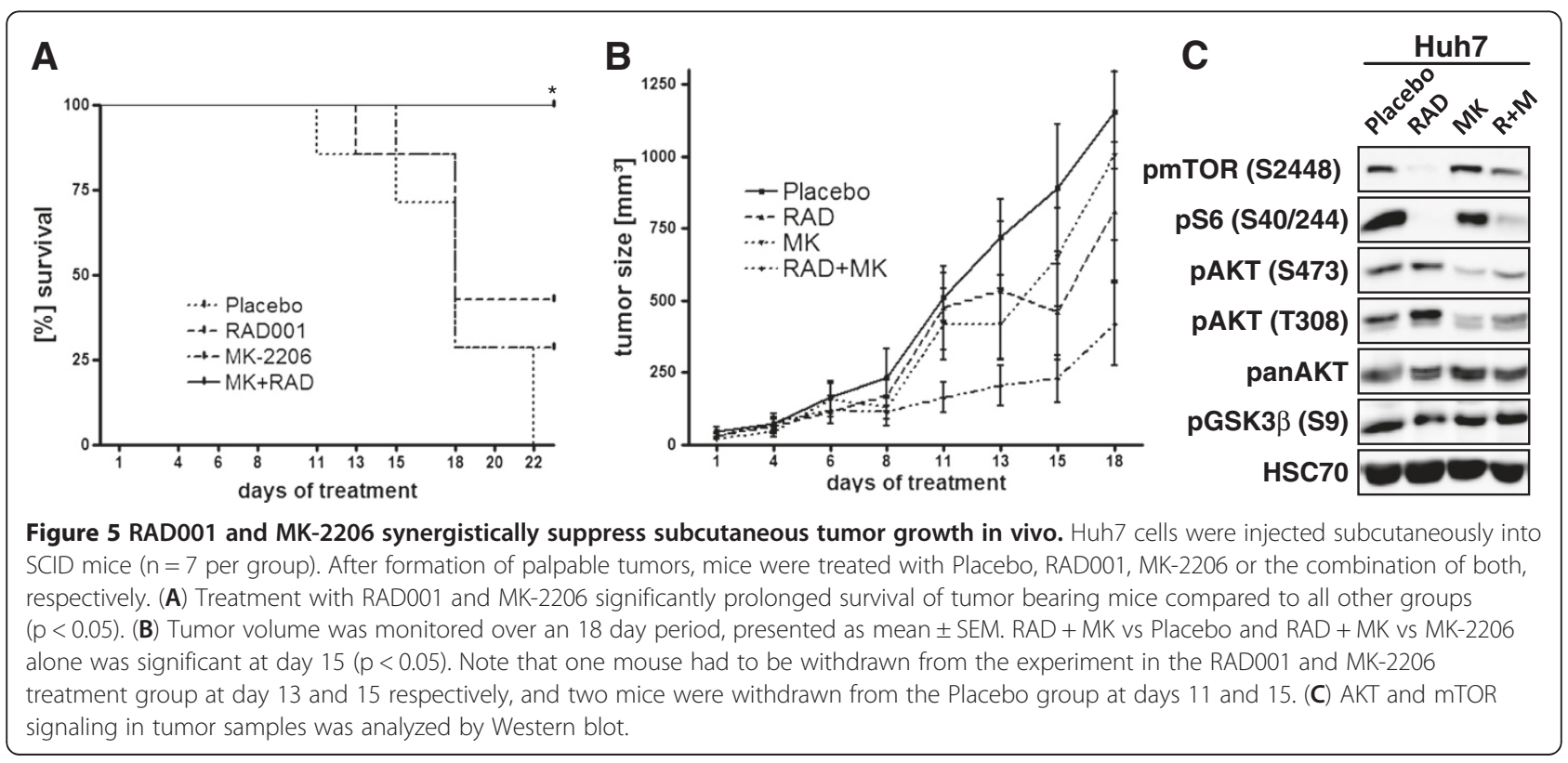


Table 1 Mutation analysis of genes encoding PI3K, mTOR and AKT isoforms in primary HCC samples

\begin{tabular}{|c|c|c|c|c|c|c|}
\hline $\begin{array}{l}\text { Patient } \\
\text { ID } \\
\end{array}$ & PI3KR1 & PI3KCA & mTOR & AKT1 & AKT2 & AKT3 \\
\hline $\mathrm{H} 282$ & & & $6909 \mathrm{~g}>\mathrm{ga}$ & & & \\
\hline H358 & $978 \mathrm{~g}>\mathrm{ga}$ & & & & & \\
\hline $\mathrm{H} 43$ & & & $6909 \mathrm{~g}>\mathrm{ga}$ & & & \\
\hline \multicolumn{7}{|l|}{ H146 } \\
\hline $\mathrm{H} 219$ & $978 \mathrm{~g}>\mathrm{ga}$ & & & & & \\
\hline $\mathrm{H} 279$ & $978 \mathrm{~g}>\mathrm{ga}$ & & $6909 \mathrm{~g}>\mathrm{ga}$ & & & \\
\hline $\mathrm{H} 292$ & $1176 c>c t$ & $3140 a>g$ & $6909 \mathrm{~g}>\mathrm{ga}$ & & & \\
\hline H361 & & & $6909 \mathrm{~g}>\mathrm{ga}$ & & & \\
\hline H59 & & & $6909 \mathrm{~g}>\mathrm{ga}$ & & & \\
\hline H326 & & & & & & \\
\hline
\end{tabular}

NCBI SNP database revealed that genetic alterations detected in PIK3R1 and mTOR (FRAP1) are SNPs. One somatic mutation was identified in PIK3CA encoding the catalytic subunit of PI3K in tumor sample H292 (exon 20, 3140 a > g; H1047R).

To further gain insight into the state of AKT activation and signaling in HCC in vivo, tumor samples used for sequencing have additionally been analysed on protein level by western blotting (Figure 6A). As expected, we observed heterogeneous expression profiles of phosphorylated AKT. AKT was activated in two out of ten investigated HCC samples, and functional AKT signaling in these two tumor samples was further confirmed by a concomitant phosphorylation of the AKT downstream ubstrate GSK3 $\beta$ (S9).

The activation status of AKT isoforms was further analysed by AKT isoform specific in vitro kinase assays. As shown in Figure 6B, AKT isoform expression does not correlate with AKT isoform activity, indicating that AKT isoforms are differentially activated independent of their expression level in vivo. Furthermore, we demonstrated for the first time that the H1047R mutant in the catalytic subunit of PI3K led to elevated activity of all AKT isoforms in comparison to healthy liver tissue of the patient (see patient H292, Table 1). These results indicate that all AKT isoforms become activated by the oncogenic hot spot H1047R mutant of PI3K in HCC.

\section{Discussion}

In this study, we aimed to investigate the PI3K/AKT/ mTOR signaling pathway in hepatocellular carcinoma by highlighting the feedback activation of AKT and its distinct isoforms following mTOR inhibition by RAD001. Further, we analyzed the activation status of specific AKT isoforms in HCC samples and corresponding healthy liver tissue as well as their diverse implications in terms of

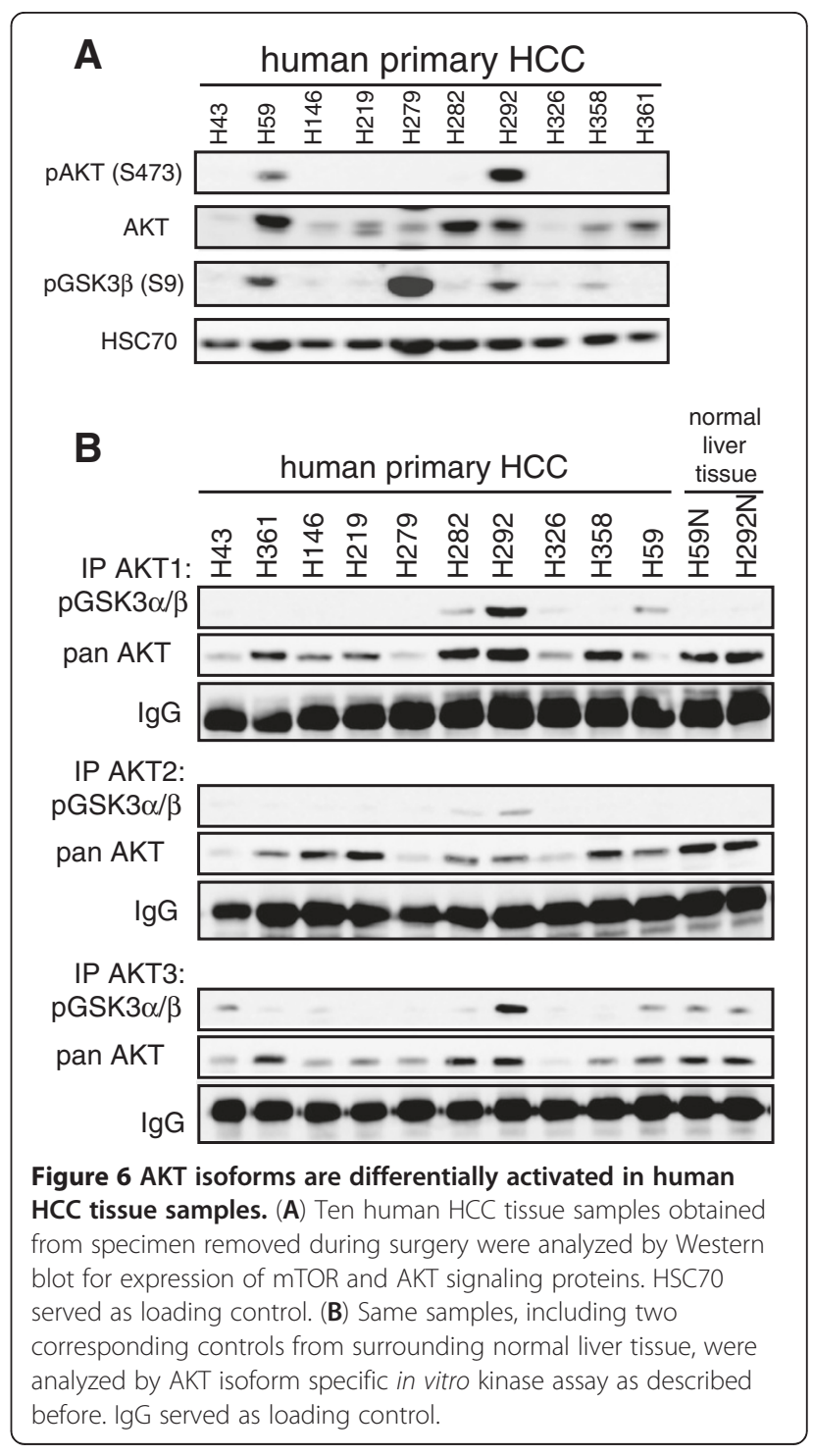


proliferation of HCC cell lines. In order to draw a light on genetic alterations of PI3K/AKT/mTOR signaling in hepatocellular carcinoma, DNA sequencing of human tumor samples were performed. The molecular events leading to activation of the PI3K/AKT/mTOR signaling cascade are not fully understood. In general, mutations in mTOR are rare. Two single amino acid substitutions in TOR1 (FRB domain) have been identified in yeast, exhibiting resistance to caffeine [37]. In addition, a point mutation in TOR2 (FRB domain) was found leading to a weak rapamycin resistance [38]. On humans, two oncogenic mutations of mTOR have been reported so far in colorectal and renal carcinoma [39,40]. Genetic aberrations in AKT itself have not yet been identified in $\mathrm{HCC}$ patients. In contrast, mutations in PIK3CA, the gene encoding for the catalytic subunit of PI3K, have been described in up to $35 \%$ of patients with HCC [41-43]. Our mutational analysis of ten human HCCs revealed no genetic alteration in $\mathrm{mTOR}$ or in any of the AKT isoforms. One somatic "hot spot" mutation of PI3K was detected in the gene PIK3CA (exon 20, 3140 a > g [H1047R]). Moreover, we analyzed the expression and activity of AKT isoforms in these tumor samples. Although all AKT isoforms were expressed in HCC samples, results revealed that $\mathrm{AKT}$ activity is often confined to particular $\mathrm{AKT}$ isoforms and independent of AKT isoform expression. In this study, we demonstrate for the first time that the oncogenic and well characterized H1047R mutant of PIK3CA, leading to constitutive activation of PI3K [44], results in elevated activity of all three AKT isoforms in comparison to healthy liver tissue of this patient. These data indicate that all AKT isoforms become activated by mutant PI3K (H1047R) in HCC. Whether all AKT isoforms are involved in the oncogenic signalling has to be shown in further experiments.

Our data further demonstrate that combining mTOR inhibitor RAD001 and AKT inhibitor MK-2206 shows a strong synergistic effect on the proliferation of HCC cell in vitro and in vivo. Therefore, dual targeting of AKT and mTOR might be a promising treatment option for HCC patients. Moreover, we give new insight into AKT isoform specific kinase activity and signaling after mTOR inhibition in HCC cells. Increased AKT1 kinase activity following mTOR treatment was reported before in HeLa cells [30]. However, AKT2 and AKT3 kinase activity has not been investigated. Our data demonstrate that single AKT isoforms can be differentially regulated after mTOR inhibition, as shown for HepG2 cells. Therefore, analysis of all $\mathrm{AKT}$ isoforms is necessary to understand the complex mechanism of AKT signaling. Overall, we demonstrated that a high expression level of phosphorylated AKT induced by feedback activation following mTOR inhibition can actually represent increased kinase activity of different AKT isoforms. The clinical relevance of this finding is underscored by the fact that increased AKT phosphorylation was recently observed in a significant proportion of tumor samples obtained from patients treated with RAD001 [45]. Which AKT isoforms become activated in patients treated with RAD001 has to be analyzed in further experiments.

In this study, we showed that knockdown of a single AKT isoform had only a minor effect on proliferation of HCC cells, with the most dominant effect observed for AKT1 in Hep3B cells. Although specific functions of AKT isoforms have clearly been demonstrated $[26,46]$, compensation and redundancy among AKT isoforms might limit the efficacy of AKT isoform specific inhibitors. However, further research is necessary to understand the exact effect of single AKT isoform inhibition on function and activity of remaining AKT isoforms.

Functional analysis of AKT isoforms of different tumor entities revealed specific oncogenic functions for distinct AKT isoforms [47]. Conclusively, the group of Muller demonstrated that AKT1 induced tumor growth, while AKT2 promotes metastasis of ErbB2-induced breast cancer in vivo [48]. Taking together these results suggest that cancer patients would profit more of a pan AKT inhibitor than of AKT isoform specific inhibitors. Consequently, inhibition of mTOR by RAD001 in combination with knockdown of a single AKT isoform evoked only small synergistic effects on proliferation of HCC cells and was additionally not restricted to a single AKT isoform as shown for Huh7 cells. In order to investigate dual targeting of mTOR and total AKT, we analyzed the efficacy of combination of mTOR inhibitor RAD001 with the potent pan AKT inhibitor MK-2206. In contrast to single AKT isoform knockdowns, treatment with pan AKT inhibitor MK-2206 in combination with RAD001 led to a significant, highly synergistic reduction of cell proliferation of all HCC cell lines tested. These data suggest that the inhibition of all AKT isoforms using a pan AKT inhibitor like MK-2206 is necessary to achieve profound synergistic effects in combination with the mTOR inhibitor RAD001. Highlighting the dual targeting of mTOR and AKT as an efficient therapy approach of HCC is of great clinical interest, since MK-2206 is already being tested in clinical trials and reported to be well tolerated $[49,50]$.

\section{Conclusion}

In summary, our data demonstrate that dual targeting of mTOR and AKT led to synergistic inhibition of proliferation of HCC cell lines. Further, our results suggest that inhibition of all, rather than one specific AKT isoform is necessary to achieve bold synergistic effects on cell proliferation. In conclusion, the combination of mTOR inhibitor RAD001 and pan AKT inhibitor MK-2206 might represent a new promising treatment strategy for patients with advanced HCC. 


\section{Methods \\ Materials}

RAD001 was provided by Novartis (Basel, Switzerland). MK-2206 was obtained from Selleck Chemicals (Houston, TX, USA). Stock solutions with a concentration of $10 \mathrm{mM}$ were prepared and stored at $-80^{\circ} \mathrm{C}$. All RAD001 solutions were thawed and refrozen for a maximum of three times and then discarded. Antibodies against pan AKT, AKT1, AKT2, pAKT (S473), pAKT (T308), mTOR, pmTOR (S2448), pmTOR (S2481), Raptor, Rictor, pERK (T202/ 204), ERK, pS6 (S240/244), IRS-1 and pIRS-1 (S636/639) were purchased from Cell Signaling Technology (Danvers, MA). Antibodies against AKT2 and HSC-70 were purchased from Santa Cruz. AKT3 antibody was obtained from Millipore (Schwallbach, Germany). 7-AAD was obtained from BD Biosciences (Pharmingen, CA, USA).

\section{Cell culture}

The three hepatocellular carcinoma cell lines Hep3B, HepG2 and Huh-7 were a kind gift from Prof. Dr. H. Will at the Heinrich Pette Institute, Hamburg, Germany. All cell lines were maintained in DMEM, supplemented with $10 \%$ $(\mathrm{v} / \mathrm{v})$ FCS, and $1 \%(\mathrm{v} / \mathrm{v})$ penicillin and streptomycin. Cells were cultured at $37^{\circ} \mathrm{C}$ in a humidified atmosphere containing $5 \% \mathrm{CO}_{2}$. All cells were tested for mycoplasma contamination every $2-3$ months.

\section{Western Blot analysis}

Western blot analysis was performed as described previously [24]. Protein expression was quantified using an LAS3000 Imager from Fuji (Raytest, Straubenhardt, Germany).

\section{Lentiviral knockdown of AKT isoforms}

pLKO.1-puro vector encoding either AKT1, AKT2, AKT3 or scrambled shRNA were purchased from Sigma-Aldrich (Taufkirchen, Germany). Generation of pseudotype lentiviruses and transduction were performed as previously described [24]. Transduced cells were selected by addition of puromycin (Sigma-Aldrich, Taufkirchen, Germany) to culture medium (final concentration $1.5 \mu \mathrm{g} / \mathrm{ml}$ ) for at least two weeks before experiments were carried out.

\section{Proliferation and cell cycle assay}

Proliferation was analyzed either by flow cytometry using the BrdU APC Flow Kit (BD, Pharmingen, CA, USA) or with the colorimetric BrdU ELISA Kit $\left(\right.$ Roche $^{\circledR}$, Basel, $\mathrm{CH})$ as indicated in the figure legends. For FACS-based assays, cells were seeded into $10 \mathrm{~cm}$ dishes and allowed to attach overnight. Then, medium was replaced by medium containing RAD001, MK-2206, a combination of both, or DMSO as control. Final DMSO concentration in culture medium was $0.1 \%(\mathrm{v} / \mathrm{v})$ in all experiments. For labeling BrdU (final concentration $10 \mu \mathrm{M}$ ) was added and cells were incubated for 12 to $16 \mathrm{~h}$. For cell cycle analysis, cells were fixed in ice cold 70\% ethanol for at least $6 \mathrm{~h}$, washed and subsequently incubated with $5 \mu \mathrm{g} 7-\mathrm{AAD}$ and $5 \mu \mathrm{g}$ RNAse A for one hour. Each experiment was performed in triplicates and has been repeated at least one time. Analysis was performed on BD Canto II flow cytometer (BD Pharmingen, CA, USA). Cell cycle analysis was performed using FlowJo 7.6.5 software.

For BrdU ELISA assays, cells were seeded into 96-well plates and allowed to attach overnight. Cells were then incubated for $72 \mathrm{~h}$ with different concentrations of MK2206, RAD001, or a combination of both. Controls were treated with DMSO only. BrdU ELISA was performed as described by the manufacturer (Becton Dickenson, Heidelberg, Germany). Each experiment was repeated at least three times in quadruplicates.

\section{Immunoprecipitation and AKT isoform specific in vitro kinase assay}

Immunoprecipitation of AKT isoforms and subsequent in vitro kinase assay was performed as described before [24]. Whole samples were analyzed by western blot technique probed with pGSK3 $\alpha / \beta$ (S9/21) and panAKT antibody. Subsequently,nitrocellulose membrane was incubated with secondary goat anti-mouse antibody (Santa Cruz Biotechnology, CA, USA) to detect mouse IgG levels for sample correction.

\section{Primary human HCC samples}

The human investigations were performed according to the Declaration of Helsinki after approval was obtained by the local ethics committee of the Medical Association Hamburg. From all patients, written informed consent was obtained prior to study related procedures. Tumor samples and samples of corresponding healthy liver tissue of HCC patients treated at the University Medical Center Hamburg Eppendorf, Department of Hepatobiliary and Transplant Surgery were stored at Indivumed (Hamburg, Germany) following the Indivumed Standard of Biobanking (http://www.indivumed.com). Genomic DNA isolation and sequence analysis was performed by Inostics (Hamburg, Germany). For protein analysis and kinase assays tissue samples were lysed by homogenisation of samples with Lysis Matrix-D (MP, USA) in NP-40 lysis buffer (containing: $50 \mathrm{mM}$ HEPES pH 7.5, $150 \mathrm{mM} \mathrm{NaCl}, 1 \% \mathrm{NP}-40,2 \%$ aprotinin, $2 \mathrm{mM}$ EDTA, $50 \mathrm{mM} \mathrm{NaF}, 10 \mathrm{mM} \mathrm{NaPPi}, 10 \%$ glycin, $1 \mathrm{mM}$ vanadate and $1 \mathrm{mM}$ PMSF) with the tissue lyser MX Pro (MP, USA).

Mutation analysis of PI3K, AKT and mTOR in HCC samples Sequence analysis of genes from $10 \mathrm{HCC}$ samples encoding the p85 $\alpha$ adapter subunit of PI3K (exon 9-17 of PIK3RI), the p110 $\alpha$ catalytic subunit of PI3K $\alpha$ (exon 2 and 10-21 of PIK3CA), mTOR (exon 44-57 of FRAP1), AKT1 (exon 3-6), AKT2 (exon 2-5) or AKT3 (exon 1-3) were 
performed by amplification of the exons with primers located in the neighboring introns by PCR and sequenced using BigDye Terminator 3.1 according to the instructions by the manufacturer (Applied Biosystems). Primer sequences can be found in Additional file 7: Table S1.

\section{Animal experiments}

All experimental protocols were approved by local authorities (Ministry of Health and Consumer Protection, Hamburg, Germany, Permit Number G52/11). 2x10^6 Huh7 cells were injected subcutaneously into SCID mice (female, age 8 weeks, $\mathrm{n}=7$ per group, obtained from Charles River, Sulzfeld, Germany). Upon establishment of palpable tumours after three weeks, mice were randomly assigned to one of the four groups (Placebo, RAD001, MK-2206, or RAD001 and MK-2206), and treatment was started. Tumor growth was monitored by regular visual inspection and tumor dimensions were measured every 2-3 days. Tumor volume was calculated using the formula longest tumor diameter $\mathrm{x}$ (shortest tumor diameter)^ $2 / 2$. RAD001, formulated as a microemulsion, was dosed at $1 \mathrm{mg} / \mathrm{kg}$ body weight and administered daily Monday through Friday. MK-2206 was formulated in a 30\% (w/v) Captisol solution and administered Monday, Wednesday and Friday dosed at $100 \mathrm{mg} / \mathrm{kg}$. A placebo microemulsion (provided by Novartis) and a 30\% (w/v) Captisol solution served as placebo. The compounds were mixed immediately before administered by gavage in a total volume of $100 \mu \mathrm{l}$. Animals were treated until termination criteria (tumor ulceration, tumor size $>2 \mathrm{~cm}$ in largest diameter, loss of body weight exceeding 20\%) were met, or for a maximum of 22 days when all mice in the placebo group had to be withdrawn. Xenograft primary tumours were harvested at necropsy and a portion of each tumor was snap frozen on liquid nitrogen for Western Blot analysis.

\section{Statistical analysis}

Student's $t$-Test (unpaired, 2-tailed) was calculated based on the data of at least three independent experiments. Bonferroni correction for multiple testing was performed where applicable. Results were considered significant if $\mathrm{p}<0.05$. All error bars represent SD. Drug interactions were analyzed based on the median effect method of Chou and Talalay [35]. CalcuSyn software (Biosoft, Cambridge, UK) was used to calculate the combination index $(\mathrm{CI})$. $\mathrm{CI}$ values from 0.3 to 0.7 are considered to indicate synergism, CI values below 0.3 are considered to represent strong synergism, and values below 0.1 very strong synergism. $\mathrm{IC}_{50}$ values were calculated using CurveExpert Professional 1.3 software. Chi-squared test was used to test for significant differences in mouse survival.

\section{Additional files}

\begin{abstract}
Additional file 1: Figure S1. No increase in AKT phosphorylated at T308 or S473 is detectable in Hep3B cells after RAD001 treatment. Hep3B cells were treated with 100 nM RAD001 up to 72 h, and cell lysates were prepared at the indicated time points. Where indicated, medium was removed after $48 \mathrm{~h}$ and replaced by fresh, $100 \mathrm{nM}$ RAD001 containing medium. Cell lysates were analyzed for AKT and mTOR signaling. HSC70 was used as loading control.
\end{abstract}

Additional file 2: Figure S2. Influence of plating density on proliferation of HCC cell lines. Increasing numbers of HCC cells were seeded into 96-wells and incubated with different concentrations of RAD001 for $72 \mathrm{~h}$. Proliferation was subsequently analyzed by BrdU incorporation. One representative experiment out of two is shown.

Additional file 3: Figure S3. Determination of $\mathrm{IC}_{50}$ for MK-2206 in HCC cell lines. HCC cells were seeded into 96 well plates and incubated with increasing concentrations of MK-2206, controls were treated with DMSO only. Proliferation was analyzed after $72 \mathrm{~h}$ by detection of BrdU

incorporation. Columns: mean of three independent experiments; bars: SD.

Additional file 4: Figure S4. Effect of RAD001 alone or in combination with MK-2206 on HCC cell proliferation. HCC cells (2,5E5 cells for Hep3B and HepG2, 2 E5 cell for Huh7) were treated with DMSO, 100 nM RAD001, $1.7 \mu$ M MK-2206, or the combination of both. The numbers of viable cells were counted using a Neubauer counting chamber and Trypane blue exclusion after 24,48 and $72 \mathrm{~h}$ treatment. The combination of both compounds inhibits cell proliferation significantly stronger than placebo or each drug alone. ${ }^{*} p<0.05$.

Additional file 5: Figure S5. Effect of single AKT isoform knockdown of AKT and mTOR signaling. HepG2 and Huh7 AKT isoform knockdown cells were treated with 100 nM RAD001, $1.7 \mu \mathrm{M}$ MK-2206, the combination of both, or DMSO, over $24 \mathrm{~h}$, and mTOR and AKT signaling pathway activity was analyzed by Western blot. HSC70 served as loading control.

Additional file 6: Figure S6. Treatment of mice bearing subcutaneous HCC-tumors had no effect on body weight. Mice treated with Placebo, RAD001, MK-2206 or both compounds in combination were weighed every other day during the first 18 day treatment period. Until day 15 , no statistically significant changes in body weight were detected. Weight loss at day 18 in MK-2206 and Placebo treated animals was due to tumor cachexia, and these animals had to be withdrawn from the experiment. Data are presented as mean \pm SEM.

Additional file 7: Table S1.Sequencing primers used for mutation analysis.

\section{Abbreviations}

mTOR: Mammalian target of rapamycin; PI3K: Phosphatidylinositol 3-kinase; PI3KCA: Catalytic subunit of phosphatidylinositol 3-kinase; IRS-1: Insulin receptor substrate 1; BrdU: 5-bromo-2/-deoxyuridine; DMSO: Dimethyl sulfoxide; PBS: Phosphate buffered saline; HCC: Hepatocellular carcinoma; $\mathrm{Cl}$ : Combination index.

\section{Competing interests}

The authors declare that they have no competing interests.

\section{Authors' contributions}

$\mathrm{NG}, \mathrm{FE}, \mathrm{BH}, \mathrm{KS}, \mathrm{US}, \mathrm{BN}$ and $\mathrm{MJ}$ designed the study. FE, NG and MJ performed the experiments and interpreted the experimental findings. FE and NG drafted the manuscript. FE, NG and MJ wrote the final version of the manuscript. All authors read and approved the final manuscript.

\section{Acknowledgements}

We would like to thank Prof. Dr. H. Will of the Heinrich Pette Institute, Hamburg, for providing the HCC cell lines, Dr. Kerstin David from Indivumed Hamburg for providing primary HCC samples and Dr. Frank Diehl from Inostics Hamburg for sequence analysis of primary HCC samples. We are grateful to Susanne Feldhaus and Tobias Gosau for technical assistance. Florian Ewald is a fellow of the University Cancer Center Hamburg (UCCH). 
Udo Schumacher is grateful for the support from the Mildred Scheel Stiftung for the animal core facility.

This study was funded by a research grant from Novartis Pharma $\mathrm{GmbH}$.

\section{Author details}

${ }^{1}$ Center for Experimental Medicine, Institute of Biochemistry and Signal Transduction, University Medical Center Hamburg-Eppendorf, Martinistr. 52, Hamburg 20246, Germany. ${ }^{2}$ Department of Hepatobiliary and Transplant Surgery, University Medical Center Hamburg-Eppendorf, Martinistr. 52, Hamburg 20246, Germany. ${ }^{3}$ Center for Experimental Medicine, Department of Anatomy and Experimental Morphology, University Cancer Center, University Medical Center Hamburg-Eppendorf, Martinistr. 52, Hamburg 20246, Germany. ${ }^{4}$ Present address: Department of Internal Medicine III, Division of Gastroenterology and Hepatology, Medical University of Vienna, Vienna, Austria. ${ }^{5}$ Present address: Department of General, Visceral and Thoracic Surgery, University Medical Center Hamburg-Eppendorf, Hamburg, Germany.

Received: 21 June 2012 Accepted: 13 November 2012

Published: 20 November 2012

\section{References}

1. Parkin DM, Bray F, Ferlay J, Pisani P: Estimating the world cancer burden: Globocan 2000. Int J Cancer 2001, 94:153-156.

2. Altekruse SF, McGlynn KA, Reichman ME: Hepatocellular carcinoma incidence, mortality, and survival trends in the United States from 1975 to 2005. J Clin Oncol 2009, 27:1485-1491.

3. Llovet JM, Ricci S, Mazzaferro V, Hilgard P, Gane E, Blanc JF, de Oliveira AC, Santoro A, Raoul JL, Forner A, et al: Sorafenib in advanced hepatocellular carcinoma. N Engl J Med 2008, 359:378-390.

4. Bhaskar PT, Hay N: The two TORCs and Akt. Dev Cell 2007, 12:487-502.

5. Engelman JA: Targeting PI3K signalling in cancer: opportunities, challenges and limitations. Nat Rev Cancer 2009, 9:550-562.

6. Villanueva A, Chiang DY, Newell P, Peix J, Thung S, Alsinet C, Tovar V, Roayaie $S$, Minguez B, Sole $M$, et al: Pivotal role of mTOR signaling in hepatocellular carcinoma. Gastroenterology 2008, 135:1972-1983. 1983 e1971-1911.

7. Chen JS, Wang Q, Fu XH, Huang XH, Chen XL, Cao LQ, Chen LZ, Tan HX, Li W, Bi J, Zhang LJ: Involvement of PI3K/PTEN/AKT/mTOR pathway in invasion and metastasis in hepatocellular carcinoma: Association with MMP-9. Hepatol Res 2009, 39:177-186.

8. Meric-Bernstam F, Gonzalez-Angulo AM: Targeting the mTOR signaling network for cancer therapy. J Clin Oncol 2009, 27:2278-2287.

9. Krueger DA, Care MM, Holland K, Agricola K, Tudor C, Mangeshkar P, Wilson KA, Byars A, Sahmoud T, Franz DN: Everolimus for subependymal giantcell astrocytomas in tuberous sclerosis. N Engl J Med 2010, 363:1801-1811.

10. Motzer RJ, Escudier B, Oudard S, Hutson TE, Porta C, Bracarda S, Grunwald V, Thompson JA, Figlin RA, Hollaender N, et al: Efficacy of everolimus in advanced renal cell carcinoma: a double-blind, randomised, placebo-controlled phase III trial. Lancet 2008, 372:449-456.

11. Zhu AX, Abrams TA, Miksad R, Blaszkowsky LS, Meyerhardt JA, Zheng H, Muzikansky A, Clark JW, Kwak EL, Schrag D, et al: Phase 1/2 study of everolimus in advanced hepatocellular carcinoma. Cancer 2011, 117:5094-5102.

12. Rizell M, Andersson M, Cahlin C, Hafstrom L, Olausson M, Lindner P: Effects of the mTOR inhibitor sirolimus in patients with hepatocellular and cholangiocellular cancer. Int J Clin Oncol 2008, 13:66-70.

13. O'Reilly KE, Rojo F, She QB, Solit D, Mills GB, Smith D, Lane H, Hofmann F, Hicklin DJ, Ludwig DL, et al: mTOR inhibition induces upstream receptor tyrosine kinase signaling and activates Akt. Cancer Res 2006, 66:1500-1508

14. Tabernero J, Rojo F, Calvo E, Burris H, Judson I, Hazell K, Martinelli E, Ramon y Cajal S, Jones S, Vidal L, et al: Dose- and schedule-dependent inhibition of the mammalian target of rapamycin pathway with everolimus: a phase I tumor pharmacodynamic study in patients with advanced solid tumors. J Clin Oncol 2008, 26:1603-1610.

15. Shi $Y$, Yan H, Frost $P$, Gera J, Lichtenstein A: Mammalian target of rapamycin inhibitors activate the AKT kinase in multiple myeloma cells by up-regulating the insulin-like growth factor receptor/insulin receptor substrate-1/phosphatidylinositol 3-kinase cascade. Mol Cancer Ther 2005, 4:1533-1540.
16. Wan X, Harkavy B, Shen N, Grohar P, Helman LJ: Rapamycin induces feedback activation of Akt signaling through an IGF-1R-dependent mechanism. Oncogene 2007, 26:1932-1940.

17. Chandarlapaty S, Sawai A, Scaltriti M, Rodrik-Outmezguine V, Grbovic-Huezo $\mathrm{O}$, Serra V, Majumder PK, Baselga J, Rosen N: AKT inhibition relieves feedback suppression of receptor tyrosine kinase expression and activity. Cancer Cell 2011, 19:58-71.

18. Toker A, Yoeli-Lerner M: Akt signaling and cancer: surviving but not moving on. Cancer Res 2006, 66:3963-3966.

19. Fresno Vara JA, Casado E, de Castro J, Cejas P, Belda-Iniesta C, GonzalezBaron M: PI3K/Akt signalling pathway and cancer. Cancer Treat Rev 2004, 30:193-204.

20. Brodbeck D, Hill MM, Hemmings BA: Two splice variants of protein kinase $B$ gamma have different regulatory capacity depending on the presence or absence of the regulatory phosphorylation site serine 472 in the carboxyl-terminal hydrophobic domain. J Biol Chem 2001, 276:29550-29558.

21. Brodbeck D, Cron P, Hemmings BA: A human protein kinase Bgamma with regulatory phosphorylation sites in the activation loop and in the C-terminal hydrophobic domain. J Biol Chem 1999, 274:9133-9136.

22. Chen WS, Xu PZ, Gottlob K, Chen ML, Sokol K, Shiyanova T, Roninson I, Weng W, Suzuki R, Tobe K, et al: Growth retardation and increased apoptosis in mice with homozygous disruption of the Akt1 gene. Genes Dev 2001, 15:2203-2208.

23. Cho H, Mu J, Kim JK, Thorvaldsen JL, Chu Q, Crenshaw EB 3rd, Kaestner KH, Bartolomei MS, Shulman GI, Birnbaum MJ: Insulin resistance and a diabetes mellitus-like syndrome in mice lacking the protein kinase Akt2 (PKB beta). Science 2001, 292:1728-1731.

24. Grabinski N, Bartkowiak K, Grupp K, Brandt B, Pantel K, Jucker M: Distinct functional roles of Akt isoforms for proliferation, survival, migration and EGF-mediated signalling in lung cancer derived disseminated tumor cells. Cell Signal 2011, 23:1952-1960.

25. Santi SA, Lee H: Ablation of Akt2 induces autophagy through cell cycle arrest, the downregulation of p70S6K, and the deregulation of mitochondria in MDA-MB231 cells. PLoS One 2011, 6:e14614.

26. Endersby R, Zhu X, Hay N, Ellison DW, Baker SJ: Nonredundant functions for Akt isoforms in astrocyte growth and gliomagenesis in an orthotopic transplantation model. Cancer Res 2011, 71:4106-4116.

27. Hirai H, Sootome H, Nakatsuru Y, Miyama K, Taguchi S, Tsujioka K, Ueno Y, Hatch H, Majumder PK, Pan BS, Kotani H: MK-2206, an allosteric Akt inhibitor, enhances antitumor efficacy by standard chemotherapeutic agents or molecular targeted drugs in vitro and in vivo. Mol Cancer Ther 2010, 9:1956-1967

28. Rosner M, Siegel N, Valli A, Fuchs C, Hengstschlager M: mTOR phosphorylated at S2448 binds to raptor and rictor. Amino Acids 2010, 38:223-228.

29. Copp J, Manning G, Hunter T: TORC-specific phosphorylation of mammalian target of rapamycin (mTOR): phospho-Ser2481 is a marker for intact mTOR signaling complex 2. Cancer Res 2009, 69:1821-1827.

30. Sarbassov DD, Ali SM, Sengupta S, Sheen JH, Hsu PP, Bagley AF, Markhard $\mathrm{AL}$, Sabatini DM: Prolonged rapamycin treatment inhibits mTORC2 assembly and Akt/PKB. Mol Cell 2006, 22:159-168.

31. Wang $X$, Yue $P$, Kim YA, Fu H, Khuri FR, Sun SY: Enhancing mammalian target of rapamycin (mTOR)-targeted cancer therapy by preventing mTOR/raptor inhibition-initiated, mTOR/rictor-independent Akt activation. Cancer Res 2008, 68:7409-7418.

32. Liao Y, Hung MC: Physiological regulation of Akt activity and stability. Am J Transl Res 2010, 2:19-42.

33. Scheid MP, Woodgett JR: Unravelling the activation mechanisms of protein kinase B/Akt. FEBS Lett 2003, 546:108-112.

34. Awada A, Cardoso F, Fontaine C, Dirix L, De Greve J, Sotiriou C, Steinseifer J, Wouters C, Tanaka C, Zoellner U, et al: The oral mTOR inhibitor RAD001 (everolimus) in combination with letrozole in patients with advanced breast cancer: results of a phase I study with pharmacokinetics. Eur J Cancer 2008, 44:84-91.

35. Chou TC, Talalay P: Quantitative analysis of dose-effect relationships: the combined effects of multiple drugs or enzyme inhibitors. Adv Enzyme Regul 1984, 22:27-55.

36. Di Nicolantonio F, Arena S, Tabernero J, Grosso S, Molinari F, Macarulla T, Russo M, Cancelliere C, Zecchin D, Mazzucchelli L, et al: Deregulation of the 
PI3K and KRAS signaling pathways in human cancer cells determines their response to everolimus. J Clin Invest 2010, 120:2858-2866.

37. Reinke A, Chen JC, Aronova S, Powers T: Caffeine targets TOR complex I and provides evidence for a regulatory link between the FRB and kinase domains of Tor1p. J Biol Chem 2006, 281:31616-31626

38. Ohne Y, Takahara T, Hatakeyama R, Matsuzaki T, Noda M, Mizushima N, Maeda T: Isolation of hyperactive mutants of mammalian target of rapamycin. J Biol Chem 2008, 283:31861-31870.

39. Hardt M, Chantaravisoot N, Tamanoi F: Activating mutations of TOR (target of rapamycin). Genes to cells: devoted to molecular \& cellular mechanisms 2011, 16:141-151.

40. Sato T, Nakashima A, Guo L, Coffman K, Tamanoi F: Single amino-acid changes that confer constitutive activation of MTOR are discovered in human cancer. Oncogene 2010, 29:2746-2752.

41. Lee JW, Soung YH, Kim SY, Lee HW, Park WS, Nam SW, Kim SH, Lee JY, Yoo $\mathrm{NJ}$, Lee SH: PIK3CA gene is frequently mutated in breast carcinomas and hepatocellular carcinomas. Oncogene 2005, 24:1477-1480.

42. Tanaka Y, Kanai F, Tada M, Asaoka Y, Guleng B, Jazag A, Ohta M, Ikenoue T, Tateishi K, Obi S, et al: Absence of PIK3CA hotspot mutations in hepatocellular carcinoma in Japanese patients. Oncogene 2006, 25:2950-2952.

43. Boyault S, Rickman DS, de Reynies A, Balabaud C, Rebouissou S, Jeannot E, Herault A, Saric J, Belghiti J, Franco D, et al: Transcriptome classification of $\mathrm{HCC}$ is related to gene alterations and to new therapeutic targets. Hepatology 2007, 45:42-52

44. Kang S, Bader AG, Vogt PK: Phosphatidylinositol 3-kinase mutations identified in human cancer are oncogenic. Proc Natl Acad Sci U S A 2005, 102:802-807.

45. Meric-Bernstam F, Akcakanat A, Chen H, Do KA, Sangai T, Adkins F, Gonzalez-Angulo AM, Rashid A, Crosby K, Dong M, et al: PIK3CA/PTEN mutations and Akt activation as markers of sensitivity to allosteric mTOR inhibitors. Clin Cancer Res 2012, 18:1777-1789.

46. Gonzalez E, McGraw TE: Insulin-modulated Akt subcellular localization determines Akt isoform-specific signaling. Proc Natl Acad Sci U S A 2009, 106:7004-7009.

47. Gonzalez E, McGraw TE: The Akt kinases: isoform specificity in metabolism and cancer. Cell Cycle 2009, 8:2502-2508.

48. Ursini-Siegel J, Schade B, Cardiff RD, Muller WJ: Insights from transgenic mouse models of ERBB2-induced breast cancer. Nat Rev Cancer 2007, 7:389-397.

49. Pal SK, Reckamp K, Yu H, Figlin RA: Akt inhibitors in clinical development for the treatment of cancer. Expert Opin Investig Drugs 2010, 19:1355-1366.

50. Yap TA, Yan L, Patnaik A, Fearen I, Olmos D, Papadopoulos K, Baird RD, Delgado L, Taylor A, Lupinacci L, et al: First-in-man clinical trial of the oral pan-AKT inhibitor MK-2206 in patients with advanced solid tumors. J Clin Oncol 2011, 29:4688-4695.

doi:10.1186/1476-4598-11-85

Cite this article as: Grabinski et al:: Combined targeting of AKT and mTOR synergistically inhibits proliferation of hepatocellular carcinoma cells. Molecular Cancer 2012 11:85.

\section{Submit your next manuscript to BioMed Central and take full advantage of:}

- Convenient online submission

- Thorough peer review

- No space constraints or color figure charges

- Immediate publication on acceptance

- Inclusion in PubMed, CAS, Scopus and Google Scholar

- Research which is freely available for redistribution 